\title{
Damage Diagnosis in 3D Structures Using a Novel Hybrid Multiobjective Optimization and FE Model Updating Framework
}

\author{
Nizar Faisal Alkayem $\left(\mathbb{D},{ }^{1}\right.$ Maosen Cao $\mathbb{D}^{1},{ }^{1}$ and Minvydas Ragulskis $\mathbb{D}^{1,2}$ \\ ${ }^{1}$ Department of Engineering Mechanics, Hohai University, Nanjing, Jiangsu 210098, China \\ ${ }^{2}$ Department of Mathematical Modeling, Kaunas University of Technology, Kaunas, Lithuania \\ Correspondence should be addressed to Maosen Cao; cmszhy@hhu.edu.cn
}

Received 31 December 2017; Revised 30 June 2018; Accepted 9 July 2018; Published 19 September 2018

Academic Editor: Ana Meštrović

Copyright (C) 2018 Nizar Faisal Alkayem et al. This is an open access article distributed under the Creative Commons Attribution License, which permits unrestricted use, distribution, and reproduction in any medium, provided the original work is properly cited.

\begin{abstract}
Structural damage detection is a well-known engineering inverse problem in which the extracting of damage information from the dynamic responses of the structure is considered a complex problem. Within that area, the damage tracking in 3D structures is evaluated as a more complex and difficult task. Swarm intelligence and evolutionary algorithms (EAs) can be well adapted for solving the problem. For this purpose, a hybrid elitist-guided search combining a multiobjective particle swarm optimization (MOPSO), Lévy flights (LFs), and the technique for the order of preference by similarity to ideal solution (TOPSIS) is evolved in this work. Modal characteristics are employed to develop the objective function by considering two subobjectives, namely, modal strain energy (MSTE) and mode shape (MS) subobjectives. The proposed framework is tested using a well-known benchmark model. The overall strong performance of the suggested method is maintained even under noisy conditions and in the case of incomplete mode shapes.
\end{abstract}

\section{Introduction}

Structural health monitoring (SHM) and failure diagnosis have recently witnessed increasing attention because of its importance for guaranteeing the integrity and service perfection of a structure. One of the main research foci of SHM is damage detection in structures under service, in which a preliminary assessment of damage is conducted to ensure the reliability and persistent performance of the structure. The evolution of structural damage detection techniques has been mainly inspired by the invention of accurate sensors and transducers in addition to improvements in signal processing techniques, which in combination were applied to nondestructive vibrational testing that reveals the dynamic characteristics of a structure. Those dynamic characteristics carry the changes in real structural parameters that in turn illustrate the existence and rate of structural damage [1-3].

Structural damage could be defined as variations between the FE model of a structure and the structure inservice that brings the concept of FE model updating into a picture [4]. FE model updating can provide an efficient way of tracking damage in structures under service. For a structural damage identification problem, the structural parameters related to the FE model of a structure are slightly and gradually regulated and dynamic responses are registered. Thereafter, distortions between the model's and measured dynamic responses are minimized until a relative consistency is reached. During that process, such local modifications can indicate damage in the studied structure. The minimization task can be thought through by utilizing efficient optimization algorithms [5-7].

In order to integrate the FE model updating into a structural damage tracking procedure, the basic task is to establish the dynamic characteristic subobjectives. The developed subobjectives are milestones in formulating the objective function that addresses the optimization problem of damage characterization. Modal analysis can provide an effective manner for gathering dynamic features. Mode shapes (MSs) are fundamental characteristics that can give general information about the alterations that have occurred in a structure due to damage. For that reason, MS subobjective can be developed by using some correlation paradigms such as the 
modal assurance criterion (MAC) [8, 9]. Another modal property with great damage sensitivity, modal strain energy (MSTE), has been used by various researchers [10-14]. It performs efficiently when utilized for tackling damage problems in complex structures experiencing damage. Furthermore, MSTE is applicable in three-dimensional structures $[14,15]$. Hence, both mode shape-based and MSTE-based subobjectives are more than sufficient to be employed in this research.

Computational intelligence has been implemented for solving complex prediction, diagnosis, and detection problems in various fields such as mechanical engineering [16-18], computer science [19, 20], biomedical engineering $[21,22]$, and electrical engineering [23]. As major disciplines of computational intelligence, swarm intelligence and EAs are powerful stochastic optimization techniques that have been implemented for solving various engineering problems in recent years. Single-objective EAs have been widely and successfully utilized for damage localization in structures. Research has shown the efficacy of genetic algorithms (GAs), the most common form of EA [24-27]. Other representative research can be found in [28, 29]. Swarm intelligent algorithms have also been implemented for the same purpose. Ding et al. [30] developed a hybrid swarm for damage identification using modal properties with pleasing results. Qian et al. [31] implemented a hybrid PSO simplex method for delamination detection in laminated beams using a delamination parameter-based objective function with robustness and efficient performance. Kang et al. [32] as well as Gökdağ and Yildiz [33] proposed two different PSO versions to track damage with successful performance. Zhu et al. [34] developed a bird mating optimizer (BMO) in the time-frequency domain for damage detection in $2 \mathrm{D}$ structures. Other techniques have been used efficiently, as in the work of Seyedpoor et al. [35, 36]. From the above survey, it is seen that single-objective EAs have performed well in solving structural damage detection problems. Nevertheless, most applications were 1D or 2D problems.

Multiobjective EAs (MOEAs) have also been implemented by various researchers for damage localization in structures. Cha and Buyukozturk $[14,15]$ developed a MOEA for damage prognostic in three-dimensional structures. Their research outcomes showed the robustness of the proposed method even under noisy environments. Liu et al. [37] used natural frequency and MS subobjectives with the successful incorporation of the weighted sum method and a GA to perform a multiobjective optimization for damage identification. Jung et al. [38] utilized the NSGAII for damage identification in truss structures, concluding that further enhancements were needed for the proposed method to be recommended for damage deduction. NSGAII was also implemented successfully by Shabbir and Omenzetter [39]. Other representative research into the application of NSGAII for damage detection can be found in [40, 41]. Farokhzad et al. [42] compared multiobjective GA (MOGA) and modified multiobjective GA (MMOGA) for damage localization in Timoshenko beams, with remarkable results obtained from MMOGA. MOGA was also successfully employed for damage detection in truss by Jung et al. [43].
Other MOEAs have been implemented for structural damage identification, as in $[44,45]$.

A literature survey of the implementation of MOEAs showed that relevant research has rarely addressed the problem of structural damage in complex structures. Hence, further research is important to explore the effectiveness of MOEAs and swarm intelligence in structural damage localization. Moreover, it is essential to introduce more powerful algorithms that can efficiently and accurately solve the problem of damage identification in $3 \mathrm{D}$ structures. For those reasons, a novel multiobjective optimization algorithm combines the multiobjective particle swarm optimization (MOPSO), Lévy flights (LFs), and the technique for the order of preference by similarity to ideal solution (TOPSIS) with a FE model updating framework is proposed for solving the problem of damage estimation in complex 3D structures. The coherence of the proposed algorithm can be measured by the combination between the global and local search of MOPSO and LFs. Furthermore, the integration of TOPSIS inside the algorithm to iteratively select a leader solution can provide an efficient paradigm that improves the overall performance of the algorithm.

This work illustrates the application of the novel multiobjective optimization algorithm called MOLFPSO/TOPSIS applied on FE model updating for structural damage localization. Two dynamic characteristic-based subobjectives, namely, MS- and MSTE-based subobjectives, are embodied in an objective function. The proposed technique is applied on a 4-story benchmark building model. In order to examine the performance of the developed technique, two damage scenarios are studied. Furthermore, the algorithm is tested under noisy conditions in correspondence to the two damage scenarios. Also, the incomplete mode shape problem is evaluated. At last, a detailed discussion of the performance of the suggested method is presented.

\section{The Objective Function}

It has been observed that in structural damage tracking combined with the FE model updating, the most critical key point is the proper selection of dynamic characteristics that includes the changes in structural parameters due to the occurrence of structural damage. On that basis, the subobjectives of errors between the dynamic features of the $\mathrm{FE}$ model of the intact structure and those measured from the damaged structure are developed. By the formulation of those subobjectives, they can be merged in such a way that an objective function for the damage detection optimization problem can be established. In the current research, both MS- and MSTE-based subobjectives are employed and engrafted into the objective function to be solved for the damage localization.

To develop the MS subobjective, a correlation technique should be employed [8]. One of the most commonly used correlation techniques is the MAC [46]. The MAC measures the uniformity between two vectors, one of which being a reference MS and the other a measured MS. The MAC matrix can be stated as 


$$
\operatorname{MAC}\left(\left\{\varphi_{I}\right\},\left\{\varphi_{D}\right\}\right)=\frac{\left|\left\{\varphi_{I}^{*}\right\}^{T}\left\{\varphi_{D}\right\}\right|^{2}}{\left\{\varphi_{I}^{*}\right\}^{T}\left\{\varphi_{I}\right\}\left\{\varphi_{D}^{*}\right\}^{T}\left\{\varphi_{D}\right\}},
$$

where $\{\varphi\}$ is the MS, $I$ and $D$ represent the undamaged and the damaged structures, respectively, and $T$ and $*$ are the transpose and the conjugate. It is defined that full correlation is observed when MAC is one and no correlation is deduced when MAC is zero.

The MS subobjective can be expressed as

$$
F_{1}\left(\varphi^{I}, \varphi^{D}\right)=\sum_{i=1}^{M}\left(1-\operatorname{diag}\left(\operatorname{MAC}_{i}\left(\left\{\varphi_{i}^{I}\right\},\left\{\varphi_{i}^{D}\right\}\right)\right),\right.
$$

where $F_{1}\left(\varphi^{I}, \varphi^{D}\right)$ is the MS subobjective, $i$ is the MS number, and $M$ is the total number of MSs diag is the diagonal element of MAC.

MSTE can serve as a sensitive indicator of structural damage. In a large-scale complex structure, MSTE can hold better information about the existence and position of minor damage than other modal characteristics. One of the most commonly occurring types of structural damage can be thought of as a stiffness lessening [47]. In spite of the reality that stiffness alterations cannot reflect all sorts of structural damage, it can be adopted in this research to simulate linearly structural damage. Consequently, by handling the MSs of the structure and the stiffness matrix $\mathbf{K}$ of the model, the MSTEs corresponding to healthy and damaged structures can be defined as

$$
\begin{aligned}
\operatorname{MSTE}_{i}^{I}\left(\varphi_{i}^{I}, K\right) & =\frac{1}{2} \varphi_{i}^{I^{T}} K \varphi_{i}^{I}, \\
\operatorname{MSTE}_{i}^{D}\left(\varphi_{i}^{D}, K\right) & =\frac{1}{2} \varphi_{i}^{D^{T}} K \varphi_{i}^{D},
\end{aligned}
$$

where $\operatorname{MTTE}_{i}^{I}$ and $\operatorname{MSTE}_{i}^{D}$ are the MSTEs of the robust and deteriorated structures for the $i$ th MS, respectively. The global MSTE subobjective can be written as

$$
F_{2}\left(\varphi^{I}, \varphi^{D}, K\right)=\sum_{i=1}^{M}\left(1-\frac{\varphi_{i}^{I^{T}} K \varphi_{i}^{I}}{\varphi_{i}^{D^{T}} K \varphi_{i}^{D}}\right)^{2},
$$

where $F_{2}$ is the MSTE subobjective. Based on the above description, the overall hybrid objective function is built as

$$
\begin{array}{r}
\operatorname{Min}\left(F_{1}, F_{2}\right)=\operatorname{Min}\left(\sum _ { i = 1 } ^ { M } \left(1-\operatorname{diag}\left(\operatorname{MAC}_{i}\left(\left\{\varphi_{i}^{I}\right\},\left\{\varphi_{i}^{D}\right\}\right)\right),\right.\right. \\
\left.\sum_{i=1}^{M}\left(1-\frac{\varphi_{i}^{I^{T}} K \varphi_{i}^{I}}{\varphi_{i}^{D^{T}} K \varphi_{i}^{D}}\right)^{2}\right) .
\end{array}
$$

Damage causes changes in the mechanical parameters of a structure [48]. The parametric changes can be directly used to track damage by performing a FE model updating framework $[8,14]$. Commonly, to select the appropriate updating parameters that can be used as damage indicators, the possible damage patterns must be defined depending on the structure under consideration and loading conditions. Some recommendations can be followed before choosing the updating parameters. First, greater importance should be assigned to the positions where structural damage is more likely to exist. Then, dynamic characteristics that are more damage-sensitive must be considered. Finally, efforts should be made to reduce the size of the updating parameter set so that the overall complexity of the problem can be tackled, by ignoring structural parameters that do not illustrate possible existing damage scenarios $[49,50]$.

One of the most widely used parameterization methods is to adopt the material and geometrical properties directly [51]. Material properties can be chosen as damage indexes for tracking structural damage, because the stiffness and mass matrices are proportional to material properties. A useful strategy is to develop a vector of damage indexes for all elements (el) as $\Theta=\left[\theta_{1}, \theta_{2}, \ldots, \theta_{\text {el }}\right]$, where $\theta \epsilon[0,1]$. If we choose a damage conductor as $v, \Theta$ is utilized to reflect the variations between the FE model parameter $v^{I}$ and the parameter $v^{U}$ related to damage simulation. The damage parameter can be defined as

$$
v_{i}^{U}=v_{i}^{I}\left(1-\theta_{i}\right)
$$

and the changes in model's elemental matrixes $\mathbf{M}$ and $\mathbf{K}$ can be written as

$$
\begin{aligned}
M_{i}^{U} & =M_{i}^{I}+\Delta M_{i}, \\
K_{i}^{U} & =K_{i}^{I}+\Delta K_{i}, \\
\Delta M_{i} & =v_{i}^{U} \cdot M_{i}^{I}, \\
\Delta K_{i} & =v_{i}^{U} \cdot K_{i}^{I},
\end{aligned}
$$

where $\Delta M_{i}$ and $\Delta K_{i}$ are the deviations in model's matrixes.

To examine the performance of the proposed MOLFPSO/ TOPSIS, the structural damage is presumed to be a reduction of some elements' moduli of elasticity $(E)$. It is important to mention that reductions in $E$ cannot mimic all sorts of structural damage, but it can be used to simulate damage to check the performance and robustness of the proposed technique.

\section{Structural Damage Localization Framework}

To tackle the structural damage estimation problem, it is essential to organize the optimization problem into two main divisions: the single-objective EAs and the MOEAs. The key points to understand the differences between the two divisions can be shown in $[52,53]$.

Structural damage tracking using MOEAs and FE model updating is shown in Figure 1. We summarize the framework as follows: initially, a FE model of the robust structure is evolved and the damage indicators are selected. Then, the framework is partitioned into two subprocesses. The former is the damage simulation process where the damagesimulated MSTE and MS subobjectives can be deduced. The second subprocess is to perform the minimization task applied on the objective function. The detailed overall framework can be well observed in [52]. 


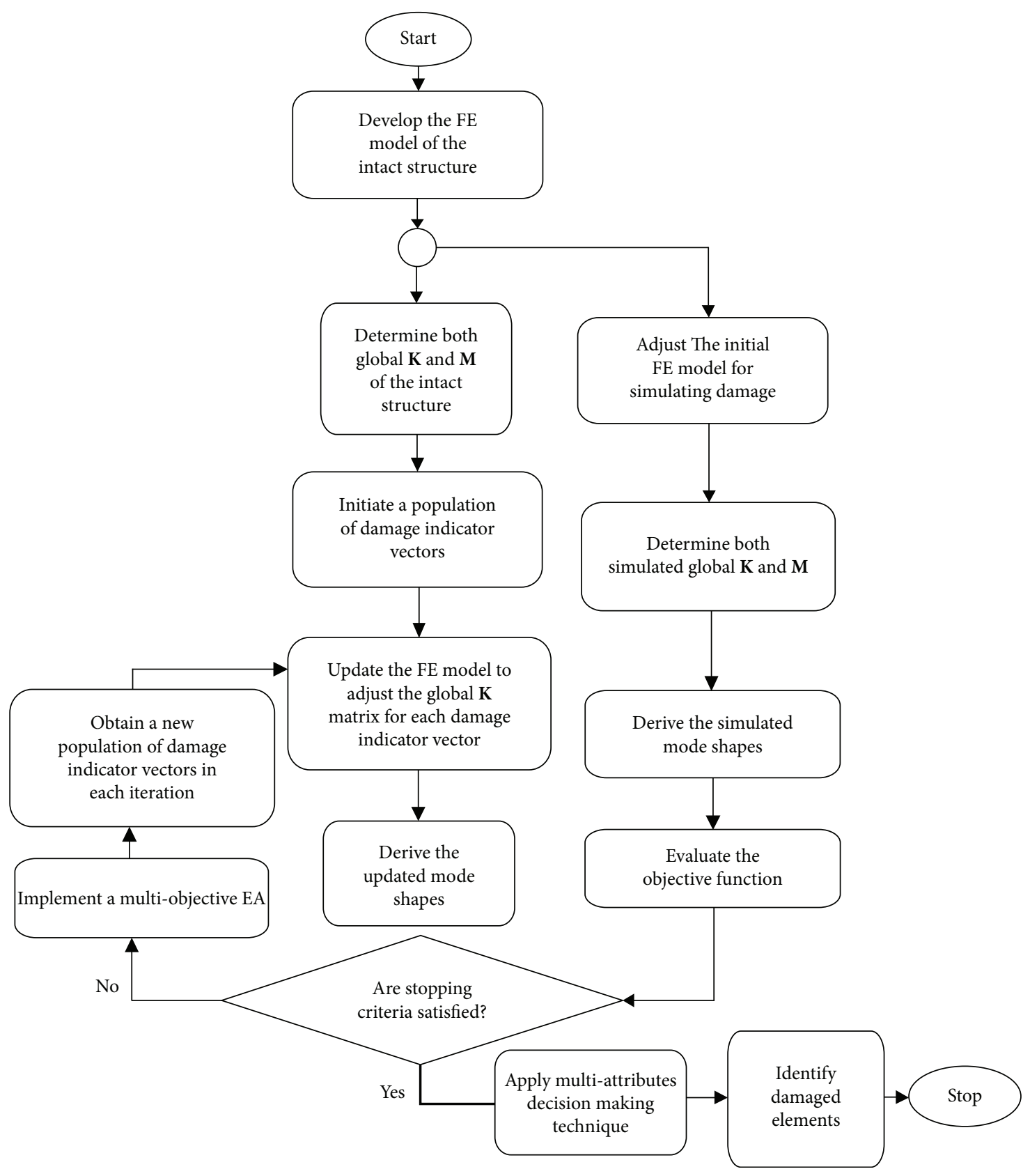

FIGURE 1: Damage prognostic paradigm using the MOEAs and FE model updating.

\section{The MOLFPSO/TOPSIS}

By following back to the excellent research conducted by Cha and Buyukozturk [14, 15], it is observed that one dynamic characteristic has been used inside the multiobjective optimization problem by dividing the MSTE-based objective function into two subobjectives. In the current research, an improvement is suggested by adding an extra subobjective that relies on the MSs. The use of independent mode shape subobjective can study the alterations in the structure independent from the stiffness matrix utilized in MSTE and without losing the benefit of damage detectability when only MSTE is utilized. This can help to improve the overall ability of the damage identification procedure when noisy conditions exist as well as when the complete MSs cannot be obtained. Moreover, because MSTE can describe only the linear type of structural damage, adding the mode shape term can enhance the damage deducibility of other types.

The MOLFPSO/TOPSIS algorithm combines various paradigms and concepts to perform a strong and reliable multiobjective optimization framework to solve complex problems comprising the problem of damage tracking in structures with FE model updating. To provide a comprehensive elucidation of the developed method, some preliminary concepts and techniques must be explained. Firstly, Lévy 
1. Create a population of random solutions Pop and corresponding speeds Vel.

2. Initialize an external archive $A c$ and define a memory of flight experience for each individual, i.e. Pbest.

3. Evaluate Pop using the multi-objective functions.

4. Find the non-dominated solutions and store them in Ac.

5. Develop hypercubes of the search space and distribute the individuals within the hypercubes using the multi-objective function values.

6. Apply TOPSIS on Ac to determine the leader solution or the global best individual Gbest.

7. While stopping criteria are not satisfied do:

a) Generate a new population $A$ by using LFs using a modified version of Eq. (9) as:

$$
\begin{gathered}
s=a_{0}\left(\text { Gbest }-x_{G, i}\right) \oplus \operatorname{Lévy}(\lambda) \sim 0.01\left(u /|v|^{1 / \lambda}\right)\left(\text { Gbest }-X_{G, i}\right) \\
\overline{P_{i+1}}=P_{i}+s
\end{gathered}
$$

b) Evaluate all particles in $A$, compare $A$ with Pop using the non-domination criterion and update Pop.

c) Generate a new population $B$ by using PSO as:

$$
\begin{gathered}
V_{i}^{t+1}=W \times V_{i}^{t}+r_{1} \times\left(\text { Pbest }_{i}-P_{i}\right)+r_{2} \times\left(\text { Gbest }-P_{i}\right), \\
P_{i+1}=P_{i}+v_{i}^{t+1},
\end{gathered}
$$

where $p_{i}$ is the current particle; $v_{i}$ is the particle's velocity; $w$ is the inertia factor; $r_{1}$ and $r_{2}$ are acceleration coefficients; $r_{1}$ and $r_{2}$ imply random numbers $\in[0,1] ; t$ is the current generation number.

d) Evaluate all particles in $B$, compare $B$ with Pop using the non-domination criterion and update Pop.

e) Remove the non-dominated solutions and fill the empty positions with randomly created solutions as:

$$
\begin{gathered}
\operatorname{In}_{i}=\operatorname{randper}\left(P_{\text {new }, i}\right), \\
\overline{P_{\text {new }, i}}=\operatorname{rnd}(0,1)+P_{\text {new }}\left(\operatorname{In}_{i}\right),
\end{gathered}
$$

where randper is a Gaussian random permutation operator; $P_{\text {new }, i}$ is the $i^{\text {th }}$ removed dominated solution; $r n d$ is a random number $\in[0,1]$.

f) Evaluate all particles in Pop and insert the non-dominated solution into $A c$.

g) Update the hybercubes in the current $A c$.

h) Remove the extra individuals in $A c$ by eliminating the crowded individuals within the corresponding hypercubes.

i) Apply TOPSIS on Ac to determine the global best individual Gbest.

8 End.

j) Update Pbest for all individuals.

\section{Algorithm 1}

flights (LFs) can be defined as random permutations that are capable of mimicking the random movements of creatures seeking food, reproduction, or other activities [54]. LFs can be implemented efficiently to expose unknown search space for optimization purposes. Moreover, LFs can perform both global and local searches around promising solutions that can be referred to as the exploration and exploitation of the global search space. To generate a new solution $X_{i}^{t+1}$ by LF, (8) can be used:

$$
X_{i}^{t+1}=X_{i}^{t}+s
$$

where $s$ is the step size, proposed by Yang and Deb [55]:

$$
s=a_{0}\left(x_{G, j}-x_{G, i}\right) \oplus \operatorname{Lévy}(\lambda) \sim 0.01 \frac{u}{|v|^{1 / \lambda}}\left(X_{G, j}-X_{G, i}\right)
$$

where $a_{0}$ is a constant, $X_{G, j}$ and $X_{G, i}$ are two random solutions, and $u$ and $v$ can be defined as

$$
\begin{aligned}
& u=N\left(0, \sigma_{u}^{2}\right), \\
& v=N\left(0, \sigma_{v}^{2}\right)
\end{aligned}
$$

where $\sigma_{u}=\left[\Gamma(1+\lambda) \sin (\pi \lambda / 2) / \Gamma[(1+\lambda) / 2] \lambda 2^{(\lambda-1) / 2}\right]^{1 / \beta}$ with $1 \leq \lambda \leq 2$ is an index, $\Gamma$ is a gamma function, and $\sigma_{v}=1$.

TOPSIS is a MCDM technique that was proposed by Hwang and Yoon [56]. From any decision matrix with $m$ number of alternatives and $n$ number of attributes, it chooses two sets of solutions known as the positive $\left(X^{+}\right)$and negative $\left(X^{-}\right)$ideal solutions. The solution with the best data from all the alternatives is called the positive ideal solution; similarly, the negative ideal solution has the worst data from all the alternatives. TOPSIS calculates the Euclidean distance of all points (alternatives) from two positive and negative solutions and compares them. The point that has the least Euclidean 


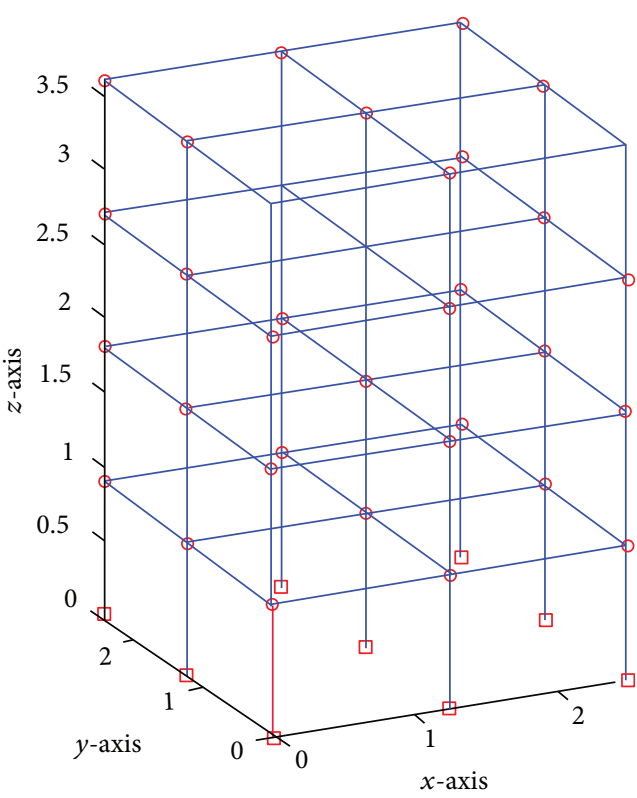

(a)

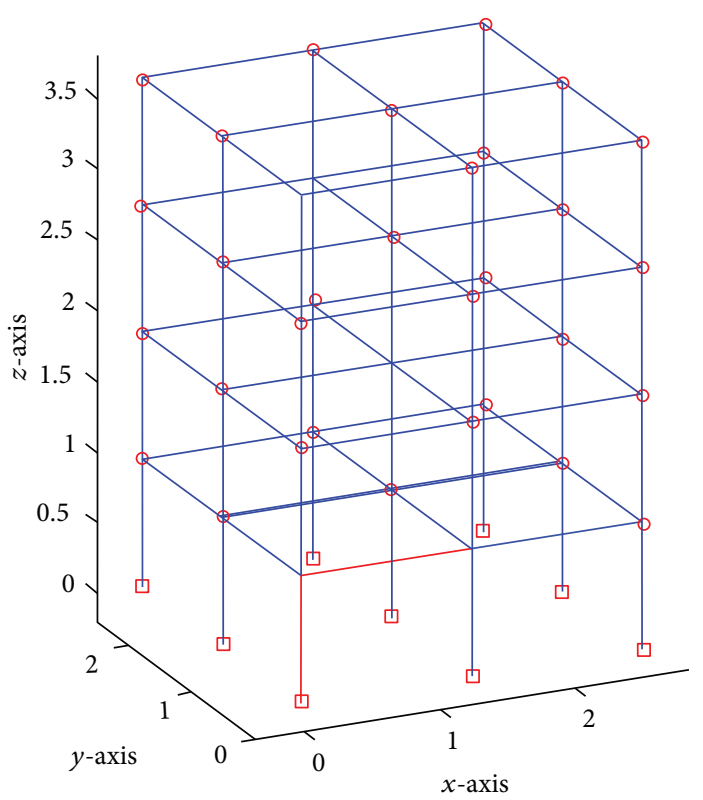

(b)

FIgURe 2: Damage scenarios: (a) scenario 1 and (b) scenario 2.

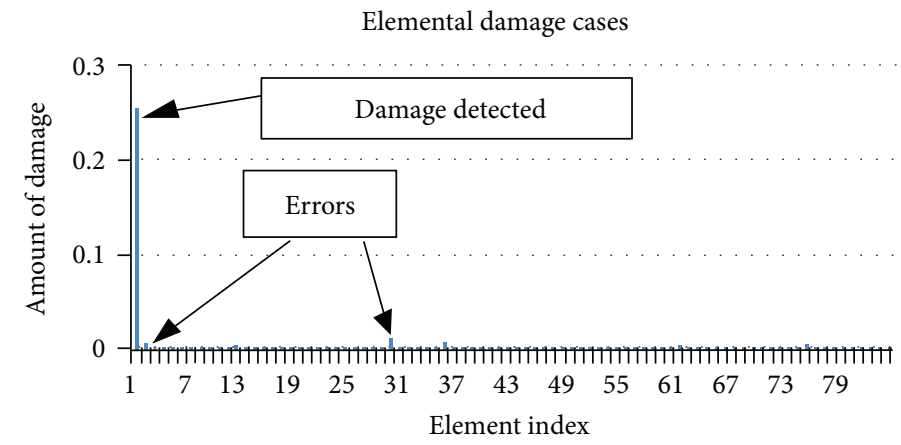

FIgURE 3: Damage locations in damage scenario 1.

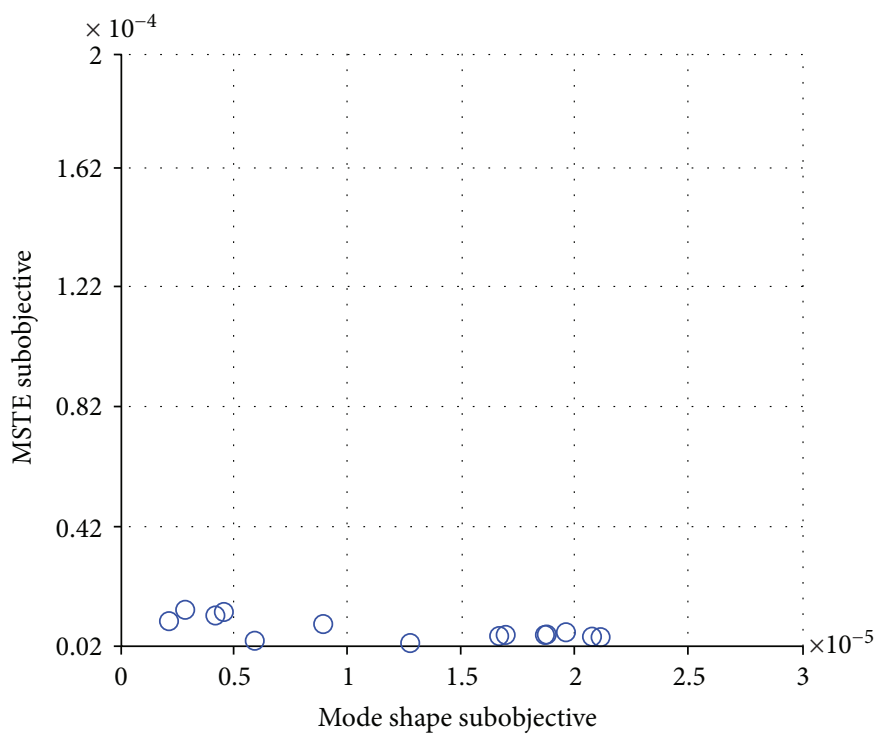

FIGURE 4: Optimal front obtained from MOLFPSO/TOPSIS in damage scenario 1. 


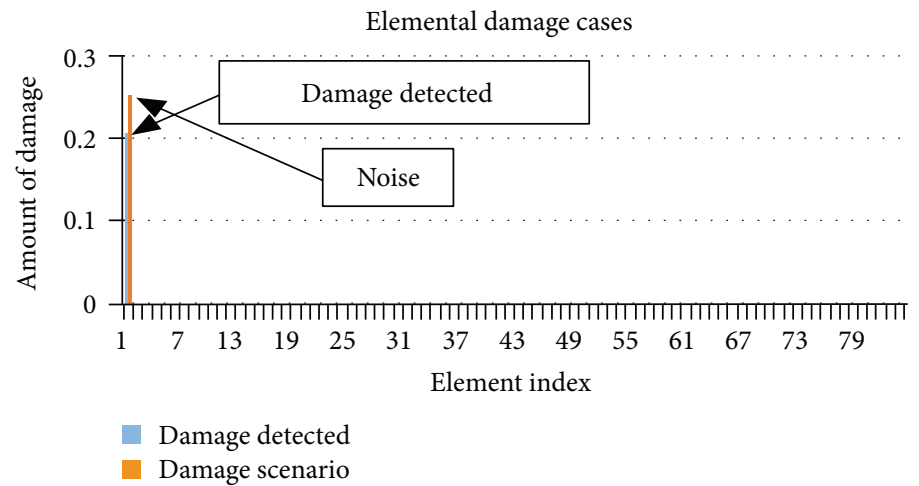

FIGURE 5: Damage positions in damage scenario 1 with noisy MSs.

distance from $\left(X^{+}\right)$and the greatest distance from $\left(X^{-}\right)$is considered the best. The steps of applying TOPSIS are as follows:

Step 1. The input $\mathbf{x}$ matrix contains $m \times n$ elements (the elements of $\mathbf{x}$ matrix are the Pareto solutions).

Step 2. To convert the dimensional problem into a nondimensional problem, a normalized decision matrix is performed from the $\mathbf{x}$ matrix.

$$
\bar{x}_{i j}=\frac{x_{i j}}{\sqrt{\sum_{i=1}^{m} x_{i j}^{2}}},
$$

where $i=1, \ldots, m$ and $j=1, \ldots, n,(m=100$ and $n=5)$.

Step 3. By assuming a set of weights for each attribute $w_{j}$ for $j=1, \ldots n$, we can find the weighted normalized decision matrix v.

$$
v_{i j}=w_{j} \bar{x}_{i j}
$$

where $\sum_{j=1}^{n} w_{j}=1$.

Step 4. Determine the positive and negative ideal solutions.

$$
\begin{aligned}
& X^{+}=\left\{v_{1}^{+}, \ldots, v_{n}^{+}\right\}, \\
& X^{-}=\left\{v_{1}^{-}, \ldots, v_{n}^{-}\right\},
\end{aligned}
$$

where $v_{j}^{+}=\left\{\max _{i} v_{i j}\left|j \in J, \min _{i} v_{i j}\right| j \in J^{\prime}\right\}$ and $v_{j}^{-}=\left\{\min _{i} v_{i j} \mid\right.$ $\left.j \in J, \max _{i} v_{i j} \mid j \in J^{\prime}\right\}$, where $J$ is the set of benefit attributes and $J^{\prime}$ is the set of cost attributes.

Step 5. Calculate the distances $d_{i}^{+}$and $d_{i}^{-}$from the positive ideal and negative ideal solution, respectively.

$$
\begin{aligned}
& d_{i}^{+}=\sqrt{\sum_{j=1}^{n}\left(v_{j}^{+}-v_{i j}\right)^{2}}, \\
& d_{i}^{-}=\sqrt{\sum_{j=1}^{n}\left(v_{j}^{-}-v_{i j}\right)^{2}},
\end{aligned}
$$

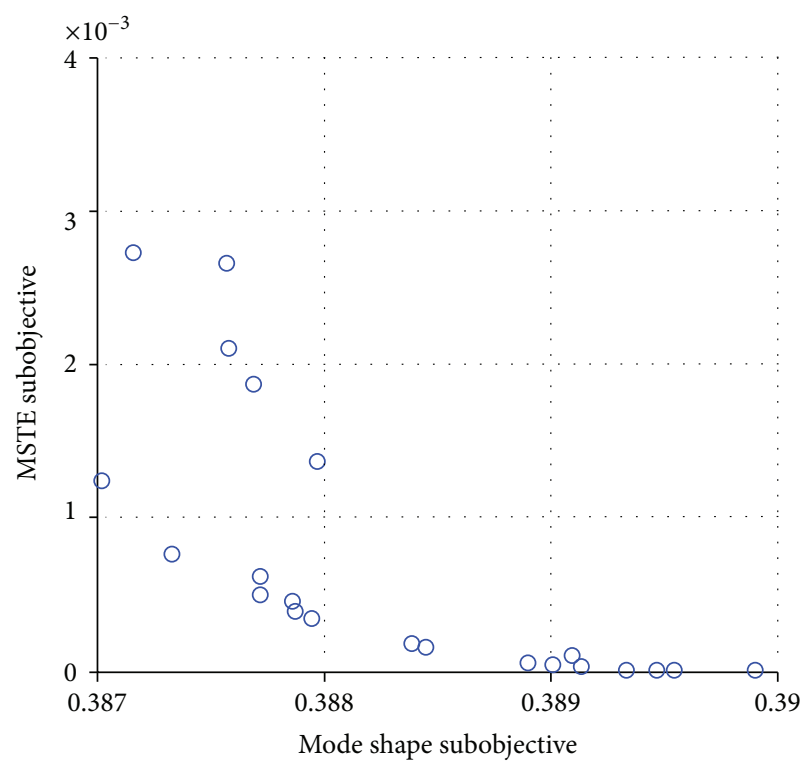

FIGURE 6: Optimal front obtained from MOLFPSO/TOPSIS in damage scenario 1 under noisy conditions.

Step 6. Determine the relative closeness of alternatives to the ideal solution.

$$
C_{i}^{+}=\frac{d_{i}^{-}}{d_{i}^{-}+d_{i}^{+}}
$$

where $0 \leq C_{i}^{+} \leq 1$ and the best solutions have relative closeness $C_{i}^{+}$closest to 1 .

MOPSO was originally proposed by Coello and Lechuga [57] and further explained by Coello and Reyes-Sierra [58]. They extended the PSO algorithm into MOPSO by employing the Pareto ranking scheme as well as initializing an archive or repository to register the superior performance of any individual in each generation by means of sets of nondominated solutions. The archive is exploited to choose a global best solution that leads the swarm to reach the Pareto front. In each generation, the archive should be updated by a spatially or geographically based process where the search space is partitioned into a set of hypercubes using multiobjective function rates. 


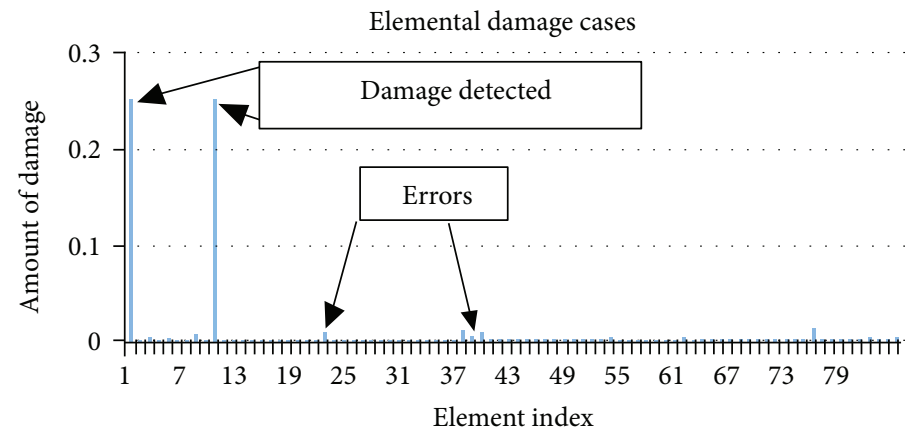

Figure 7: Damage locations in damage scenario 2.

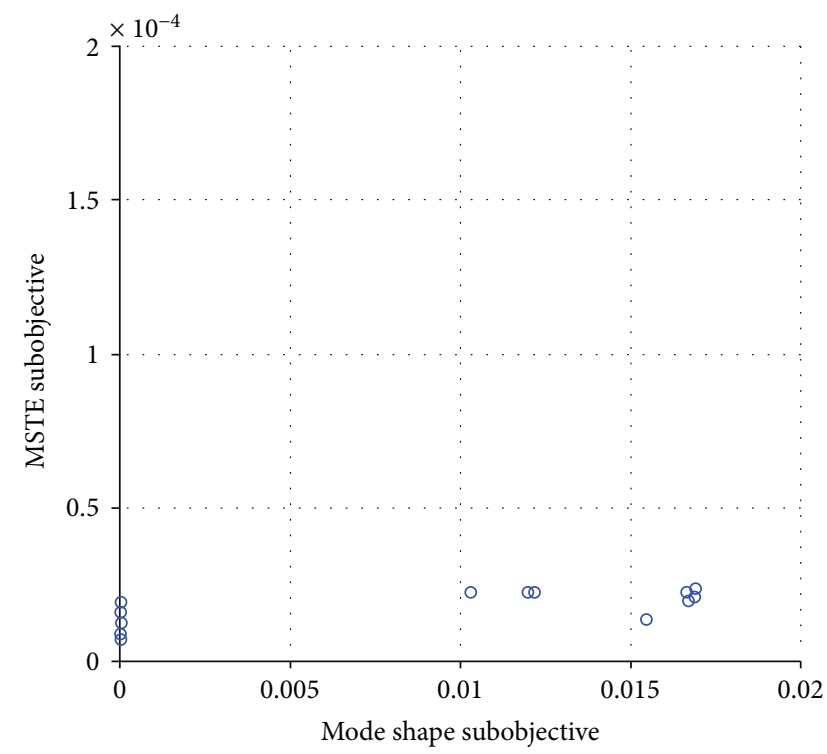

Figure 8: Optimal front obtained from MOLFPSO/TOPSIS in damage scenario 2 .

The proposed MOLFPSO/TOPSIS is designed using the above-mentioned concepts. The key point in the proposed method is to use TOPSIS to rank all solutions in the archive and to sort them to choose the leading best solution in each generation. That helps to reduce the complexity of the problem because there is no need for a MCDM at the end of the structural damage detection process when the leader solution is chosen in each generation by TOPSIS. Another advantage is that both LFs and PSO are utilized within the algorithm in such a way that there is no need for a large population size and exploration and exploitation are well performed in each generation, reducing the computational time and improving the overall efficiency and reliability. The spatial representation in MOPSO is still employed in MOLFPSO/TOPSIS for removing crowded solutions among the archive. The MOLFPSO/TOPSIS algorithm can be summarized as follows:

Although multiobjective genetic algorithms have shown a prominent performance when applied by Cha and Buyukozturk [14] for structural damage tracking and also

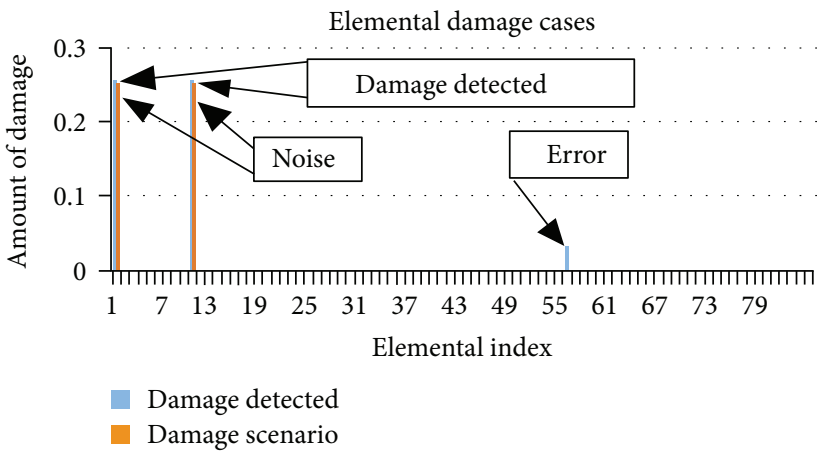

Figure 9: Damage positions in damage scenario 2 with noisy MSs.

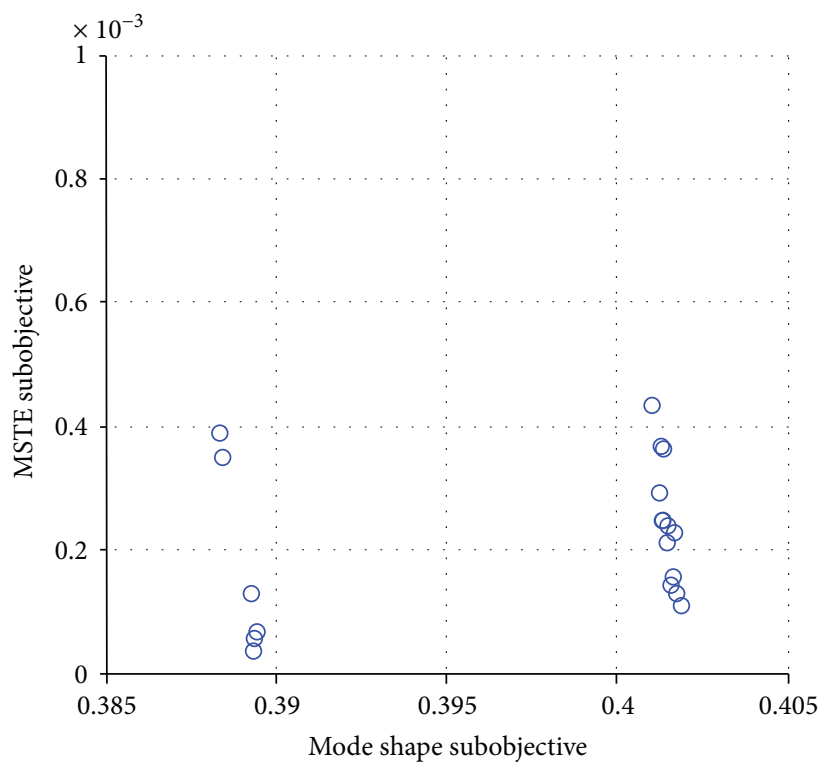

FIgUre 10: Optimal front obtained from MOLFPSO/TOPSIS in damage scenario 2 under noisy conditions.

when implemented for active control device optimal placement by Cha et al. [59], it is important to develop a stronger multiobjective optimization approach able to overcome more complexity in the structure and can not only detect but also 
TABLE 1: Numerical evaluation of the MOLFPSO/TOPSIS with FE model updating.

\begin{tabular}{lcccc}
\hline & & Min & Mean & Max \\
\hline \multirow{3}{*}{ Case 1 } & MS subobjective & $2.18 E-06$ & $1.45 E-05$ & $2.11 E-05$ \\
& MSTE subobjective & $2.975 E-06$ & $6.99 E-06$ & $1.364 E-05$ \\
& Computational time & & 2551.97823 seconds & \\
\hline \multirow{3}{*}{ Case 2 } & MS subobjective & $3.08 E-06$ & 0.012812 & 0.017029 \\
& MSTE subobjective & $7.33 E-06$ & $2.09 E-05$ & $2.56 E-05$ \\
& Computational time & & 4783.06526 seconds & \\
\hline \multirow{3}{*}{ Case 1 with $\pm 5 \%$ white noise } & MS subobjective & 0.387019 & 0.388337 & 0.390032 \\
& MSTE subobjective & $1.74 E-06$ & 0.00066 & 0.002721 \\
& Computational time & & 4912.28630 seconds & 0.401908 \\
Case 2 with $\pm 5 \%$ white noise & MS subobjective & 0.388335 & 0.398434 & $2.56 E-05$ \\
& MSTE subobjective & $7.33 E-06$ & $2.09 E-05$ & \\
\hline
\end{tabular}

determine the accurate severity of structural damage. The MOLFPSO/TOPSIS algorithm can combine the well-known global optimization feature of PSO when used for FE model updating [60] with the local search ability of LFs. Such combination can serve better when damage detection accuracy is required and complex structures are under investigation. Furthermore, the guided elitist search feature provided by TOPSIS can help to reduce the computational cost and provide better convergence towards the optimal Pareto front. Also, it makes the MCDM determine the best compromise solution unnecessary.

\section{Case Study: 3D Modular Structure}

After benchmarking the algorithm and evaluating the performance of the proposed MOLFPSO/TOPSIS algorithm, a three-dimensional model is built similar to the benchmark model $[61,62]$ as shown in Figure 2. The model's dimensions are $2.5 \mathrm{~m} \times 2.5 \mathrm{~m} \times 3.6 \mathrm{~m}$. The model's beams and columns are Euler-Bernoulli beams built of hot rolled grade $300 \mathrm{~W}$ steel with $300 \mathrm{MPa}$ nominal yield stress. The material properties of the structure are given in [62]. The model is composed of 84 elements and 45 nodes with 270 DOFs. To examine the efficiency of the developed MOLFPSO/TOPSIS technique, two damage scenarios are taken into account as in Figure 2. Damage is simulated by reducing $25 \%$ of the modulus of elasticity.

In testing the application of MOLFPSO/TOPSIS to identify damage in $3 \mathrm{D}$ structures, first, the previously mentioned objective function is utilized and the first 12 MSs are employed. Then, after several trials, MOLFPSO/TOPSIS is implemented using 50 particles and $W=0.5$. The number of hypercubes in set to 7 and repository size is 25 . In LFs, the parameters $\lambda$ and $\beta$ are set to $1.5[54,55]$. The weighting factors in (12) are set to 0.5 ; that is, both subobjectives will have similar significance. The framework is executed 20 times, and results are recorded. In damage case 1, the algorithm is proved to be able to locate the damage with very minor errors, as shown in Figure 3. The optimal front achieved by the MOLFPSO/TOPSIS is presented in Figure 4. Also, when the simulated MSs are contaminated with $\pm 5 \%$ white noise, the MOLFPSO/TOPSIS successfully tracks the damage with very few significant errors, as observed in Figure 5. The optimal front in damage case 1 with noise is illustrated in Figure 6. It is obvious that the MOLFPSO/TOPSIS can detect and locate damage in the studied structure accurately and efficiently, even under noisy conditions.

In damage case 2, which is the more difficult case, the proposed technique shows excellent performance in tracking the structural damage with insignificant errors, as shown in Figure 7. The optimal front resulting from the MOLFPSO/ TOPSIS is highlighted in Figure 8. Moreover, when $\pm 5 \%$ Gaussian noise contaminates the simulated MSs, the developed methodology shows good ability to determine damage with acceptable errors, as shown in Figure 9. For damage case 2 with noise, the optimal front is exhibited in Figure 10. It is clear from the figures that the MOLFPSO/TOPSIS combined with FE model updating can serve as a powerful and reliable framework for identifying and diagnosing damage in the $3 \mathrm{D}$ structures, even within noise-polluted environments.

To fulfill the evaluation of the overall paradigm, all result outcomes are tabulated in Table 1. All minimum, mean, and maximum values of both MS-based and MSTE-based subobjectives (subobjectives) corresponding to all Pareto solutions as well as the computational time and number of successful runs are all given in Table 1. It can be seen that the multiobjective values almost match the target zero values of the dynamic subobjectives in damage cases 1 and 2. Moreover, even in noisy environments, the increase in multiobjective values due to noise has not affected the overall performance and ability to localize structural damage. Over and above these virtues, the computational time is convenient in all cases. Only in damage case 2 with noise is the number of successful runs lower, due to difficulty in inferring damage when two damaged beams are connected perpendicularly.

Another important factor to judge the overall performance is to evaluate the problem of incomplete MSs. Two 


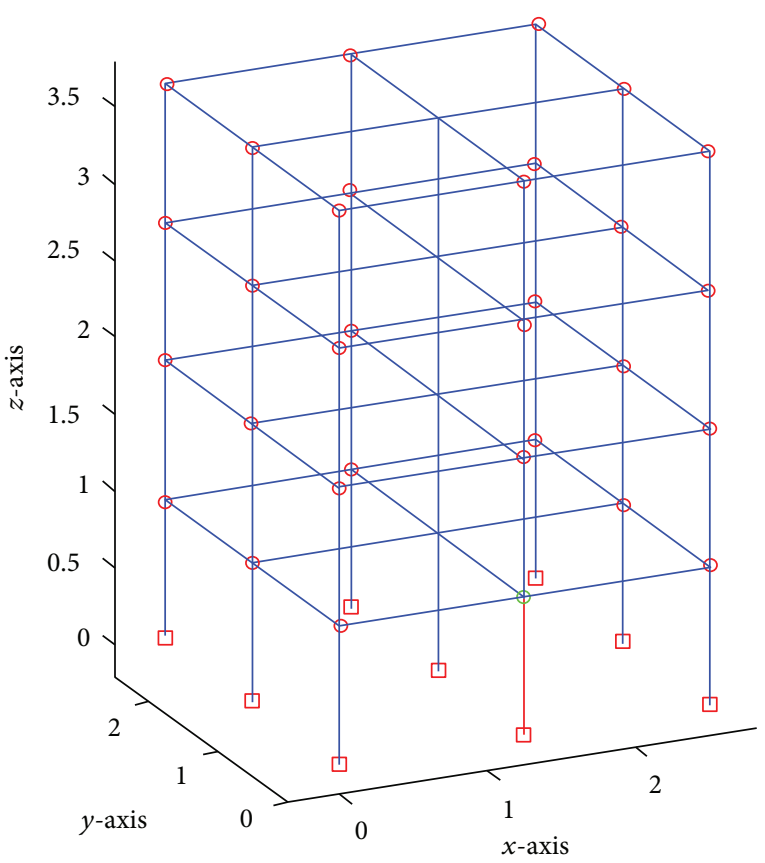

(a)

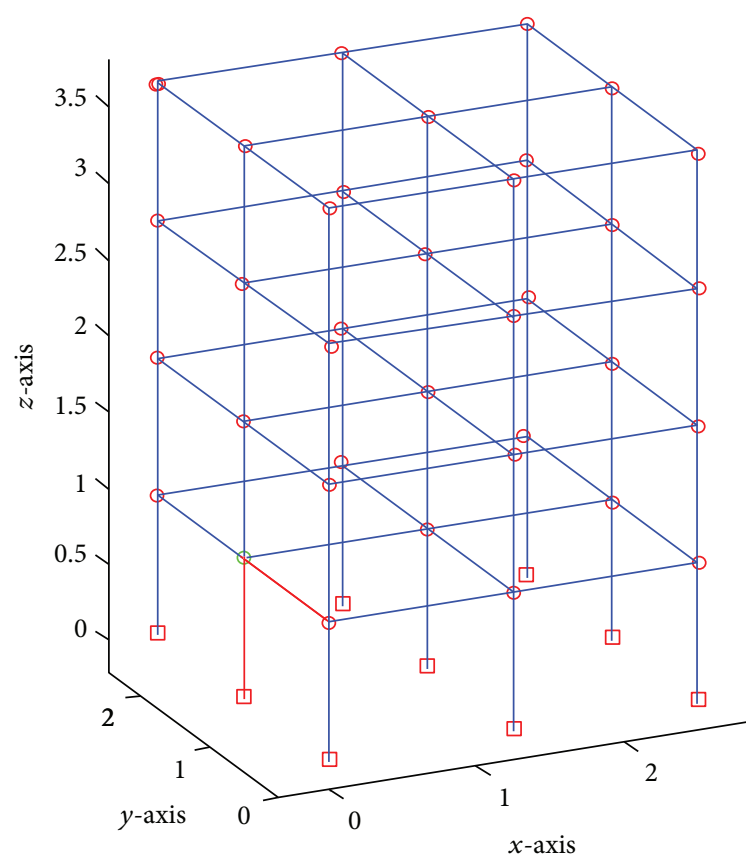

(b)

FIGURE 11: Incomplete MSs damage scenarios: (a) scenario 3 and (b) scenario 4.

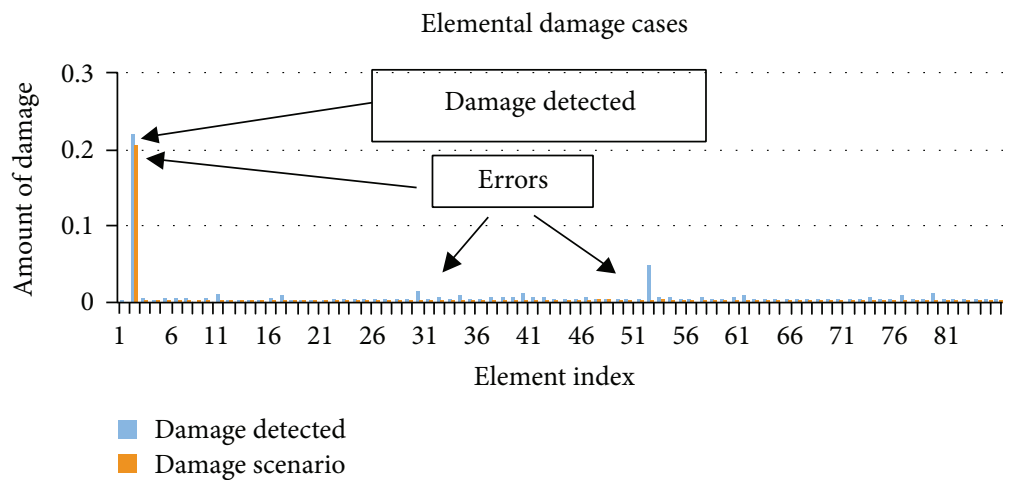

Figure 12: Damage locations in damage scenario 3.

damage scenarios are considered to study the incomplete MSs problem. Scenario 3 in which $20 \%$ damage is assigned to element 2 (red beam) and MS information are unknown at node 12 (green dot) as well as scenario 4 in which $20 \%$ damage is assigned to elements 4 and 16 (red beam) and MS information are missing at node 13 (green dot), as they are observed in Figure 11. Considering the use of the first three mode shapes, the results of damage tracking when complete MSs cannot be defined are shown in Figures 12 and 13. The results show that the proposed algorithm has proven good ability in detecting structural damage even when applied with unavailability of complete MSs. Nevertheless, it has shown inconsistent performance when executed for several times and needed almost the double computational time.

Finally, it is clear that the proposed framework has evidenced good performance when applied to damage identification in $3 \mathrm{D}$ structures. Moreover, its accuracy and relative consistency, together with its the ability to track superior solutions in a single run, make the suggested MOLFPSO/ TOPSIS with FE model updating paradigm suitable and reliable when damage localization in $3 \mathrm{D}$ structures is needed.

\section{Conclusion}

In this research, the problem of damage prognostic in threedimensional structures implementing a novel MOEA incorporated with FE model updating was investigated. The novel algorithm called MOLFPSO/TOPSIS was designed to provide an efficient and reliable structural damage localization framework. The methodology included the use of TOPSIS as a MCDM technique to select a leading solution in each iteration within the multiobjective optimization, that is, the MOLFPSO. Proper selection of such a leader solution can highly and positively influence convergence to the Pareto 


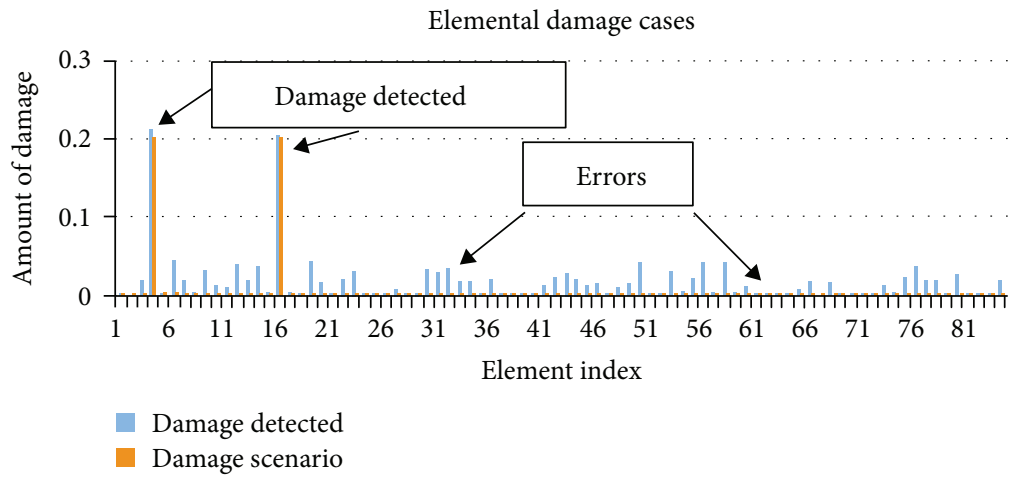

FIGURE 13: Damage locations in damage scenario 4.

front as well as saving postprocessing time when a bestcompromised solution is required. To evaluate the performance of the proposed paradigm, a three-dimensional model was deemed a case study with two simulated damage scenarios. Furthermore, in each scenario, Gaussian noise was added to contaminate the simulated MSs to examine the reliability of the developed technique under polluted conditions. Finally, the incomplete MSs problem has been evaluated with relatively good performance. The proposed technique accomplished effective damage diagnosis in $3 \mathrm{D}$ structures with accuracy, reliability, and low computational time, even when tested under a noisy environment and with the absence of complete mode shapes.

\section{Conflicts of Interest}

The authors declare that they have no conflicts of interest.

\section{Acknowledgments}

The authors appreciate the financial help provided by the Key Program of the National Natural Science Foundation of China (Grant no. 11772115) and the Jiangsu Provincial Recruitment Program of Foreign Experts (Type B, Grant 172 no. JSB2017007).

\section{References}

[1] W. Fan and P. Qiao, "Vibration-based damage identification methods: a review and comparative study," Structural Health Monitoring: An International Journal, vol. 10, no. 1, pp. 83$111,2011$.

[2] Z. X. Yuan and K. P. Yu, "Finite element model updating of damped structures using vibration test data under base excitation," Journal of Sound and Vibration, vol. 340, pp. 303-316, 2015.

[3] J. G. Chen and O. Büyüköztürk, "A symmetry measure for damage detection with mode shapes," Journal of Sound and Vibration, vol. 408, pp. 123-137, 2017.

[4] F. Seguel and V. Meruane, "Damage assessment in a sandwich panel based on full-field vibration measurements," Journal of Sound and Vibration, vol. 417, pp. 1-18, 2018.

[5] R. M. Lin, "Function-weighted frequency response function sensitivity method for analytical model updating," Journal of Sound and Vibration, vol. 403, pp. 59-74, 2017.
[6] F. Adel, S. Shokrollahi, M. Jamal-Omidi, and H. Ahmadian, "A model updating method for hybrid composite/aluminum bolted joints using modal test data," Journal of Sound and Vibration, vol. 396, pp. 172-185, 2017.

[7] M. Pedram, A. Esfandiari, and M. R. Khedmati, "Damage detection by a FE model updating method using power spectral density: numerical and experimental investigation," Journal of Sound and Vibration, vol. 397, pp. 51-76, 2017.

[8] G.-H. Kim and Y.-S. Park, “An improved updating parameter selection method and finite element model update using multiobjective optimisation technique," Mechanical Systems and Signal Processing, vol. 18, no. 1, pp. 59-78, 2004.

[9] R. Perera and A. Ruiz, "A multistage FE updating procedure for damage identification in large-scale structures based on multiobjective evolutionary optimization," Mechanical Systems and Signal Processing, vol. 22, no. 4, pp. 970-991, 2008.

[10] C. J. Carrasco, R. Osegueda, C. Ferregut, and M. Grygier, "Damage localization in a space truss model using modal strain energy," in SPIE The International Society for Optical Engineering, pp. 1786-1792, SPIE International Society For Optical, Orlando, FL, USA, 1997.

[11] Z. Y. Shi, S. S. Law, and L. M. Zhang, "Structural damage localization from modal strain energy change," Journal of Sound and Vibration, vol. 218, no. 5, pp. 825-844, 1998.

[12] Z. Y. Shi, S. S. Law, and L. M. Zhang, "Structural damage detection from modal strain energy change," Journal of Engineering Mechanics, vol. 126, no. 12, pp. 1216-1223, 2000.

[13] W.-J. Yan, T.-L. Huang, and W.-X. Ren, "Damage detection method based on element modal strain energy sensitivity," Advances in Structural Engineering, vol. 13, no. 6, pp. 1075$1088,2010$.

[14] Y.-J. Cha and O. Buyukozturk, "Structural damage detection using modal strain energy and hybrid multiobjective optimization," Computer-Aided Civil and Infrastructure Engineering, vol. 30, no. 5, pp. 347-358, 2015.

[15] Y. Cha and O. Buyukozturk, "Modal strain energy based damage detection using multi-objective optimization," in Structural Health Monitoring, vol. 5, pp. 125-133, Springer, Cham, 2014.

[16] G. Beruvides, F. Castaño, R. E. Haber, R. Quiza, and A. Villalonga, "Coping with complexity when predicting surface roughness in milling processes: hybrid incremental model with optimal parametrization," Complexity, vol. 2017, Article ID 7317254, 11 pages, 2017.

[17] J. Ma, J. Wu, and X. Wang, "Fault diagnosis method of check valve based on multikernel cost-sensitive extreme learning 
machine," Complexity, vol. 2017, Article ID 8395252, 19 pages, 2017.

[18] I. Marović, I. Sušanj, and N. Ožanić, "Development of ANN model for wind speed prediction as a support for early warning system," Complexity, vol. 2017, Article ID 3418145, 10 pages, 2017.

[19] H. Wang, Z. Zhao, Z. Guo, Z. Wang, and G. Xu, "An improved clustering method for detection system of public security events based on genetic algorithm and semisupervised learning," Complexity, vol. 2017, Article ID 8130961, 10 pages, 2017.

[20] C. S. Chin, J. Si, A. S. Clare, and M. Ma, "Intelligent image recognition system for marine fouling using Softmax transfer learning and deep convolutional neural networks," Complexity, vol. 2017, Article ID 5730419, 9 pages, 2017.

[21] L.-Y. Dai, C.-M. Feng, J.-X. Liu, C.-H. Zheng, J. Yu, and M.-X. Hou, "Robust nonnegative matrix factorization via joint graph Laplacian and discriminative information for identifying differentially expressed genes," Complexity, vol. 2017, Article ID 4216797, 11 pages, 2017.

[22] L. Yuan, C.-A. Yuan, and D.-S. Huang, "FAACOSE: a fast adaptive ant colony optimization algorithm for detecting SNP epistasis," Complexity, vol. 2017, Article ID 5024867, 10 pages, 2017.

[23] Y. Cheng, L. Tao, and C. Yang, "Lithium-ion battery capacity estimation: a method based on visual cognition," Complexity, vol. 2017, Article ID 6342170, 13 pages, 2017.

[24] X. Yong and H. Hong, "A genetic algorithm for structural damage detection based on vibration data," in IMAC XIX 19th International Modal Analysis Conference, pp. 13811387, Kissimmee, FL, USA, 2001.

[25] J. H. Chou and J. Ghaboussi, "Genetic algorithm in structural damage detection," Computers \& Structures, vol. 79, no. 14, pp. 1335-1353, 2001.

[26] F. T. K. Au, Y. S. Cheng, L. G. Tham, and Z. Z. Bai, "Structural damage detection based on a micro-genetic algorithm using incomplete and noisy modal test data," Journal of Sound and Vibration, vol. 259, no. 5, pp. 1081-1094, 2003.

[27] A. M. Raich and J. Ghaboussi, "Evolving structural design solutions using an implicit redundant genetic algorithm," Structural and Multidisciplinary Optimization, vol. 20, no. 3, pp. 222-231, 2000.

[28] R. S. He and S. F. Hwang, "Damage detection by an adaptive real-parameter simulated annealing genetic algorithm," Computers \& Structures, vol. 84, no. 31-32, pp. 2231-2243, 2006.

[29] M. I. Friswell, J. E. T. Penny, and S. D. Garvey, “A combined genetic and eigensensitivity algorithm for the location of damage in structures," Computers \& Structures, vol. 69, no. 5, pp. 547-556, 1998.

[30] Z. H. Ding, M. Huang, and Z. R. Lu, "Structural damage detection using artificial bee colony algorithm with hybrid search strategy," Swarm and Evolutionary Computation, vol. 28, pp. 1-13, 2016.

[31] X. Qian, M. Cao, Z. Su, and J. Chen, "A hybrid particle swarm optimization (PSO)-simplex algorithm for damage identification of delaminated beams," Mathematical Problems in Engineering, vol. 2012, Article ID 607418, 11 pages, 2012.

[32] F. Kang, J.-j. Li, and Q. Xu, "Damage detection based on improved particle swarm optimization using vibration data," Applied Soft Computing, vol. 12, no. 8, pp. 2329-2335, 2012.
[33] H. Gökdağ and A. R. Yildiz, "Structural damage detection using modal parameters and particle swarm optimization," Materials Testing, vol. 54, no. 6, pp. 416-420, 2012.

[34] J. J. Zhu, M. Huang, and Z. R. Lu, "Bird mating optimizer for structural damage detection using a hybrid objective function," Swarm and Evolutionary Computation, vol. 35, pp. 41-52, 2017.

[35] S. M. Seyedpoor, "A two stage method for structural damage detection using a modal strain energy based index and particle swarm optimization," International Journal of Non-Linear Mechanics, vol. 47, no. 1, pp. 1-8, 2012.

[36] S. M. Seyedpoor, S. Shahbandeh, and O. Yazdanpanah, “An efficient method for structural damage detection using a differential evolution algorithm-based optimisation approach," Civil Engineering and Environmental Systems, vol. 32, no. 3, pp. 230-250, 2015.

[37] H. Liu, K. Xin, and Q. Qi, "Study of structural damage detection with multi-objective function genetic algorithms," Procedia Engineering, vol. 12, pp. 80-86, 2011.

[38] S. Jung, S.-Y. Ok, and J. Song, "Robust structural damage identification based on multi-objective optimization," International Journal for Numerical Methods in Engineering, vol. 81, no. 6, pp. 786-804, 2010.

[39] F. Shabbir and P. Omenzetter, "Application of multi-objective optimization to structural damage estimation via model updating," in Proceedings of SPIE 8348, Health Monitoring of Structural and Biological Systems, pp. 1-10, San Diego, CA, USA, 2012.

[40] R. Perera, E. Sevillano, and A. Ruiz, "Multiobjective structural damage identification in uncertain environments," in International Conference on Structural Nonlinear Dynamics and Diagnosis, pp. 1-5, Marrakech, Morocco, 2012.

[41] P. da Silva Lopes Alexandrino, A. B. Jorge, and S. S. da Cunha Júnior, "Detection of holes in a plate using multiobjective optimization and multicriteria decision making," in 22nd International Congress of Mechanical Engineering (COBEM), pp. 2890-2900, Ribeirão Preto, SP, Brazil, 2013.

[42] R. Farokhzad, B. Mohebi, G. Ghodrati Amiri, and M. G. Ashtiany, "Detecting structural damage in Timoshenko beams based on optimization via simulation (OVS)," Journal of Vibroengineering, vol. 18, no. 8, pp. 5074-5095, 2016.

[43] S. Jung, S.-Y. Ok, and J. Song, "Structural damage identification based on multi-objective optimization," in Structural Dynamics, pp. 1239-1244, Springer, New York, NY, USA, 2010.

[44] J. Zhou, A. Mita, and L. Rongshuai, "Multi-objective optimization strategies for damage detection using cloud model theory," in Proceedings of SPIE 8348, Health Monitoring of Structural and Biological Systems 2012, pp. 1-7, San Diego, CA, USA, 2012.

[45] M. Wang and J. C. Brigham, "Assessment of multi-objective optimization for nondestructive evaluation of damage in structural components," Journal of Intelligent Material Systems and Structures, vol. 25, no. 9, pp. 1082-1096, 2014.

[46] R. Allemang and D. Brown, "A correlation coefficient for modal vector analysis," in The First International Modal Analysis Conference, pp. 110-116, Orlando, FL, USA, 1982.

[47] L. R. Barroso and R. Rodriguez, "Damage detection utilizing the damage index method to a benchmark structure," Journal of Engineering Mechanics, vol. 130, no. 2, pp. 142-151, 2004. 
[48] C. C. Ciang, J.-R. Lee, and H.-J. Bang, "Structural health monitoring for a wind turbine system: a review of damage detection methods," Measurement Science and Technology, vol. 19, no. 12, article 122001, 2008.

[49] M. Ratcliffe and N. Lieven, "An improved method for parameter selection in finite element model updating," The Aeronautical Journal, vol. 102, no. 1016, pp. 321-329, 1998.

[50] P. Avitabile, Model Updating - Endless Possibilities, Society for Experimental Mechanics, Bethel, CT, USA, 2000.

[51] M. Friswell and J. Mottershead, Finite Element Model Updating in Structural Dynamics, Springer, Dordecht, Netherlands, 1995.

[52] N. F. Alkayem, M. Cao, Y. Zhang, M. Bayat, and Z. Su, "Structural damage detection using finite element model updating with evolutionary algorithms: a survey," Neural Computing and Applications, vol. 30, no. 2, pp. 389-411, 2018.

[53] D. Savic, "Single-objective vs. multiobjective optimisation for integrated decision support," in Proceedings of the First Biennial Meeting of the International Environmental Modelling and Software Society, pp. 1-12, Lugano, Switzerland, 2002.

[54] X.-S. Yang, "Firefly algorithm, Lévy flights and global optimization," in Research and Development in Intelligent Systems XXVI, pp. 209-218, Springer, London, UK, 2010.

[55] X.-S. Yang and S. Deb, "Cuckoo search via Lévy flights," in 2009 World Congress on Nature \& Biologically Inspired Computing (NaBIC), pp. 210-214, Coimbatore, India, 2009.

[56] C. Hwang and K. Yoon, Multiple Attribute Decision Making: Methods and Applications, Springer-Verlag, New York, NY, USA, 1981.

[57] C. Coello and M. Lechuga, "MOPSO: a proposal for multiple objective particle swarm optimization," in Proceedings of the 2002 Congress on Evolutionary Computation. CEC'02 (Cat. No.02TH8600), pp. 1051-1056, Honolulu, HI, USA, 2002.

[58] C. A. Coello Coello and M. Reyes-Sierra, "Multi-objective particle swarm optimizers: a survey of the state-of-the-art," International Journal of Computational Intelligence Research, vol. 2, no. 3, 2006.

[59] Y. J. Cha, A. Raich, L. Barroso, and A. Agrawal, "Optimal placement of active control devices and sensors in frame structures using multi-objective genetic algorithms," Structural Control and Health Monitoring, vol. 20, no. 1, pp. 16-44, 2013.

[60] N. F. Alkayem and M. Cao, "Damage identification in threedimensional structures using single-objective evolutionary algorithms and finite element model updating: evaluation and comparison," Engineering Optimization, pp. 1-20, 2018.

[61] D. Bernal, S. J. Dyke, H.-F. Lam, and J. Beck, "Phase II of the ASCE Benchmark Study on SHM," in Proceedings of the 15th ASCE Engineering Mechanics Conference, pp. 1-5, New York, NY, USA, 2002.

[62] E. A. Johnson, H. F. Lam, L. S. Katafygiotis, and J. L. Beck, "Phase I IASC-ASCE structural health monitoring benchmark problem using simulated data," Journal of Engineering Mechanics, vol. 130, no. 1, pp. 3-15, 2004. 


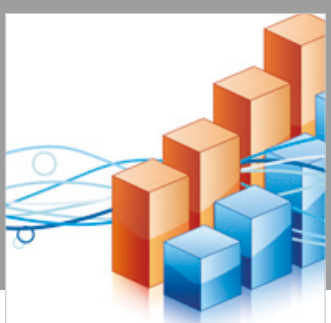

Advances in

Operations Research

\section{-n-m}
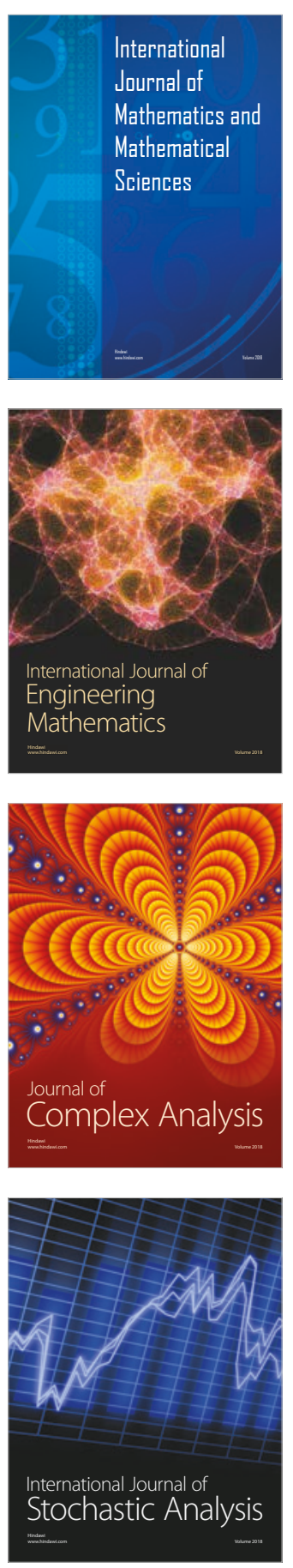
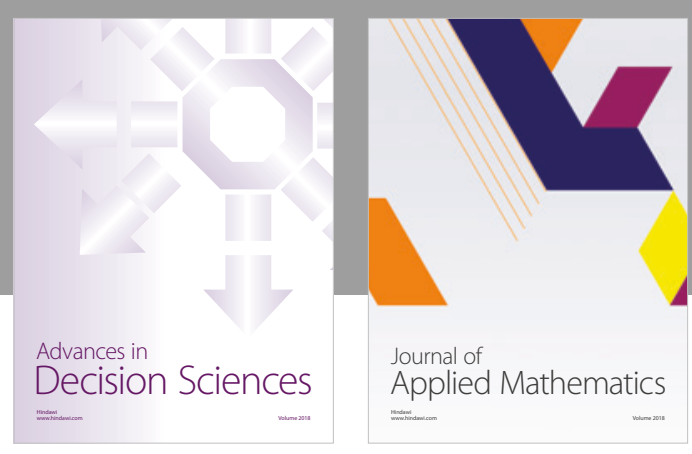

Journal of

Applied Mathematics
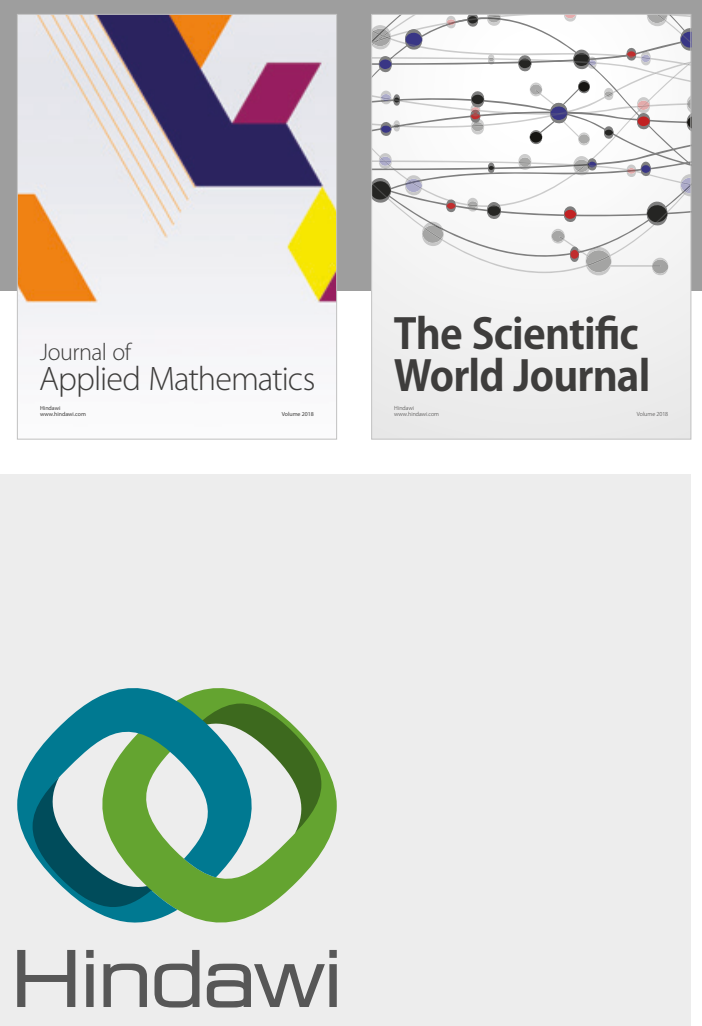

Submit your manuscripts at

www.hindawi.com

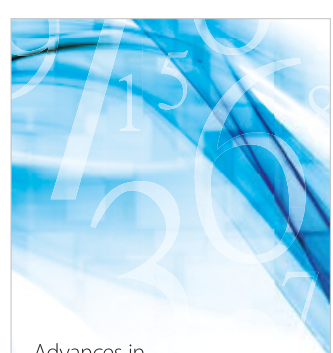

Advances in
Numerical Analysis
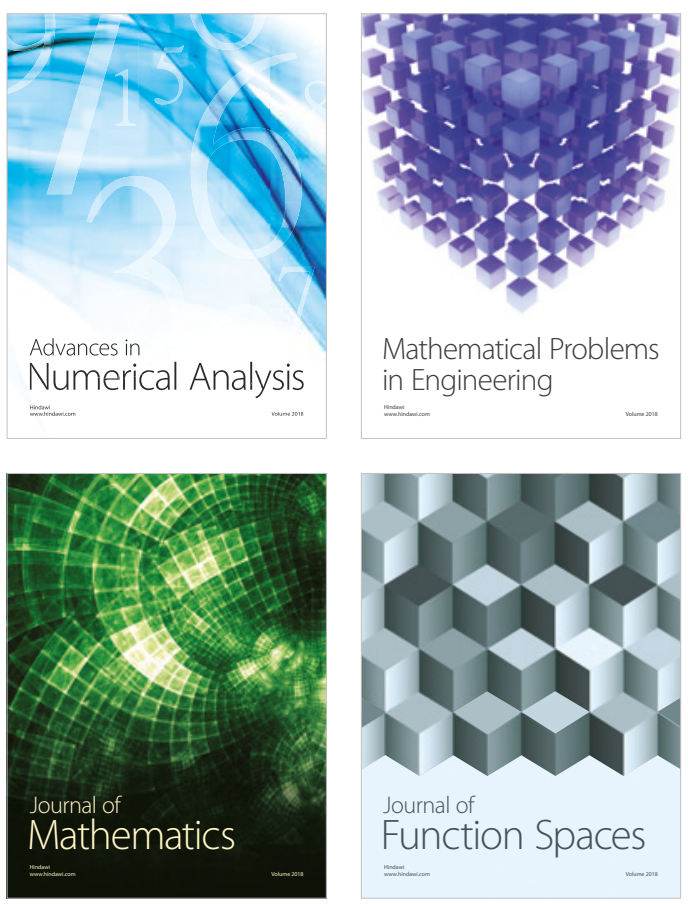

Mathematical Problems in Engineering

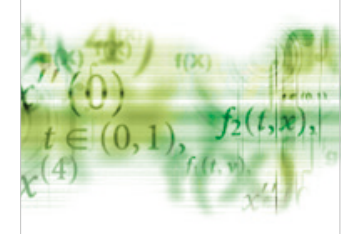

International Journal of

Differential Equations

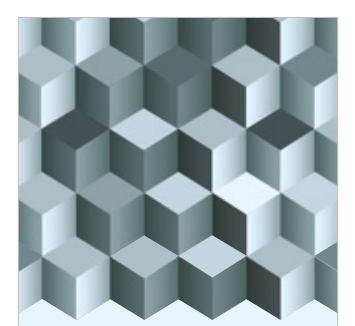

Journal of

Function Spaces
The Scientific

World Journal

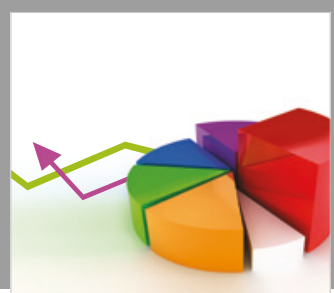

Journal of

Probability and Statistics
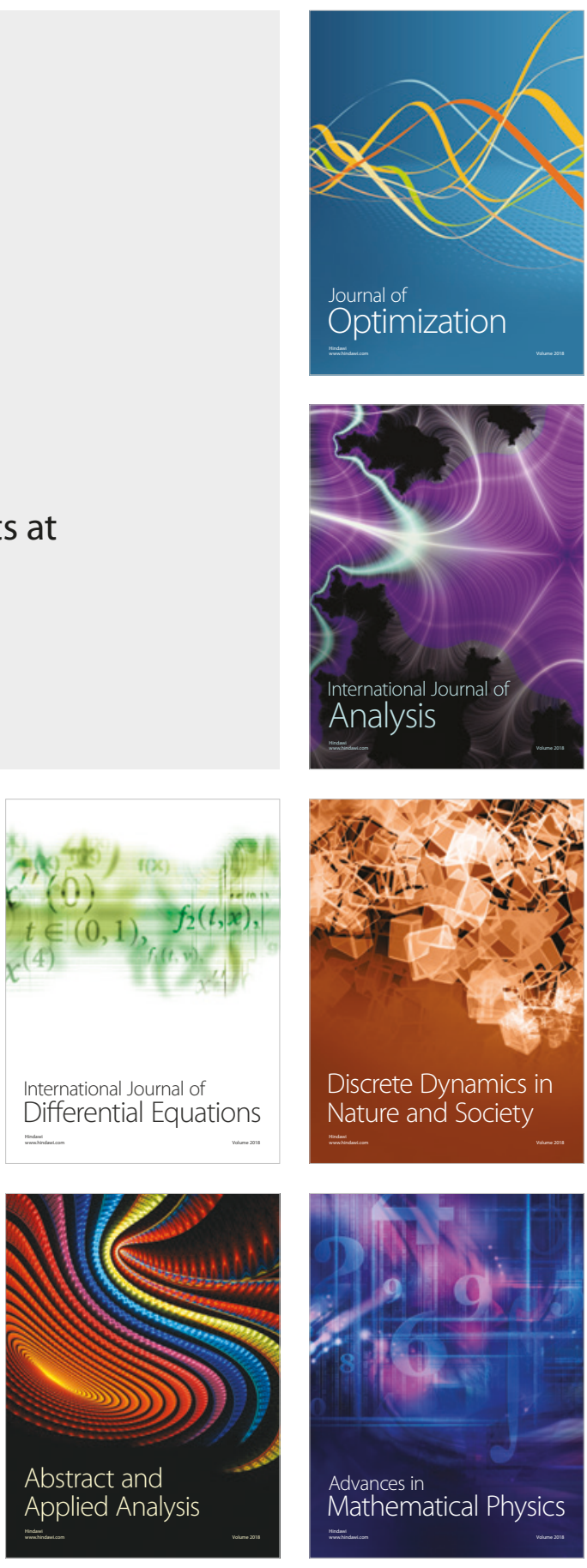